\title{
EVEKTIFITAS PEMANFAATAN RUANG TERBUKA PUBLIK DI TAMAN SULTAN HASANUDDIN GOWA
}

\author{
Irma Rahayu' ${ }^{1}$, Wahyuni Jaharuddin ${ }^{2}$ \\ ${ }^{1}$ Jurusan Teknik Arsitektur UIN Alauddin Makassar \\ ${ }^{2}$ Jurusan Teknik Arsitektur PPs Universitas Hasanuddin \\ E-mail: irmamgee@yahoo.go.id
}

\begin{abstract}
The importance of the existence of Green Open Space (RTH) in urban areas has begun to be felt by the community at this time. By looking at the phenomenon of the many public open spaces that are changing their faces into new high-rise buildings and housing, it has encouraged the enthusiasm of some people to restore the role of public space in urban areas. Various environmentalists took part, including the government through the Ministry of Public Works and Public Housing, various communities including the implementers of the 2015 world habitat day activity (HHD2015) and writers, to voice the urgency of public space and share ideas and strategies for encourage the realization of public space for all communities. Sultan Hasanuddin Park is a park located in Gowa Regency, but it is not passed by public transportation. Sultan Hasanuddin Park also has several supporting facilities but it does not function properly and some have been damaged. This study uses a qualitative descriptive method, which describes a phenomenon, events and conditions that exist. This study aims to Analyze the pattern of spatial use in Sultan Hasanuddin Park, Identify factors influencing the effectiveness of the utilization of the Sultan Hasanuddin Makassar Park facility and Analyze the utilization of supporting facilities for Sultan Hasanuddin Park as a public open space. The results showed that the Sultan Hasanuddin Park did not function properly, due to the lack of shade in the seating area, so that the upholders sat in a shaded area and not in the proper seat. The absence of a clear parking area so that the end of the park in the park and the absence of public bins so that one corner of the park used as public TPU. Lack of care I janitors who take care of the park so that plants and grasses that exist in the garden are not maintained.
\end{abstract}

Keywords: Effectiveness, Public Space, Park City, Gowa Regency

\section{PENDAHULUAN}

$\mathrm{P}$ erkembangan kota yang bergulir cepat terkadang mengabaikan kebutuhan ruang terbuka yang sangat didambakan bagi kehidupan perkotaan, dimana faktor keamanan dan kenyamanan perlu diutamakan untuk pemenuhan ruang terbuka tersebut, sebagai fasiltas interaksi sosial ruang publik diharapkan dapat mempertautkan seluruh kepentingan pengguna tanpa membedakan latar belakang ekonomi, sosial, 
budaya dalam dinamika kehidupan kota. Pertambahan penduduk daerah perkotaan mengakibatkan peningkatan kebutuhan sarana dan prasarana perkotaan terutama kebutuhan perumahan. (Panudju 1999). Pertumbuhan dan perkembangan kota yang demikian menyebabkan semakin tidak terkontrolnya permukiman baru yang menyebabkan perubahan terhadap sifat kota di kemudian hari.

Kabupaten Gowa mumpunyai taman sebagai Ruang Terbuka Publik yaitu Taman Sultan Hasanuddin yang berlokasi di Jl. Tumanurung Raya, Pandang Pandang, Kec. Somba Opu, Kabupaten Gowa, Sulawesi Selatan 92114. Tanah lapang yang diubah menjadi taman Sultan Hasanuddin seluas 1 hektar itu akan menjadi ruang publik baru. Taman Sultan Hasanuddin digarap sejak bulan April 2017. Tujuan pemerintah membentuk objek ini yaitu bukan hanya menjadi tempat refreshing serta arena olahraga ringan, namun taman Sultan Hasanuddin diharapkan juga bisa menjadi kawasan wisata kuliner baru. Penelitian ini bertujuan mengidentifikasi kondisi eksisting taman Sultan Hasanuddin dan keefektifan taman sebagai ruang terbuka publik di Kabupaten Gowa.

\section{METODE PENELITIAN}

Metode penelitian ini bersifat deskriptif yaitu suatu bentuk penelitian yang ditujukan untuk mendeskripsikan fenomena-fenomena yang ada baik fenomena alamiah, ataupun fenomena buatan manusia fenomena itu dapat berupa bentuk, aktivitas karakteristik, perubahan, hubungan, kesamaan, dan perbedaan antara fenomena, yang satu dengan fenomena yang lain. Penelitian kualitatif, data dikumpulkan dalam kondisi yang ada. Pengumpulan data yang dilakukan adalah kajian literatur, pembagian kuesioner, wawancara, dan survey lapangan. Teknik analisis yang digunakan adalah deskriptif kuantitatif dengan alat analisis pembobotan dengan Skala Likert. Adapun jenis analisis yang dugunakan dalam penelitian ini yang pertaman analisis karakteristik pengunjung berdasarkan kuisioner yang meliputi usia pengunjung, asal pengunjung, waktu berkunjung, moda transportasi yang digunakan, kedua analisis faktor-faktor yang mempengaruhi pemanfaatan ruang publik dan ketiga analisis efektivitas

\section{HASIL DAN PEMBAHASAN}

A. Gambaran Umum Taman Sultan Hasanuddin

1. Kondisi Eksisting Tamana Sultan Hasanuddin

Taman Sultan Hasanuddin yang terletak di Jl. Tumanurung Raya, Pandang Pandang, Kec. Somba Opu, Kabupaten Gowa, Sulawesi Selatan 92114. Tanah lapang yang diubah menjadi Taman Sultan Hasanuddin seluas 1 hektar. Taman Sultan Hasanuddin digarap sejak bulan April 2017. 


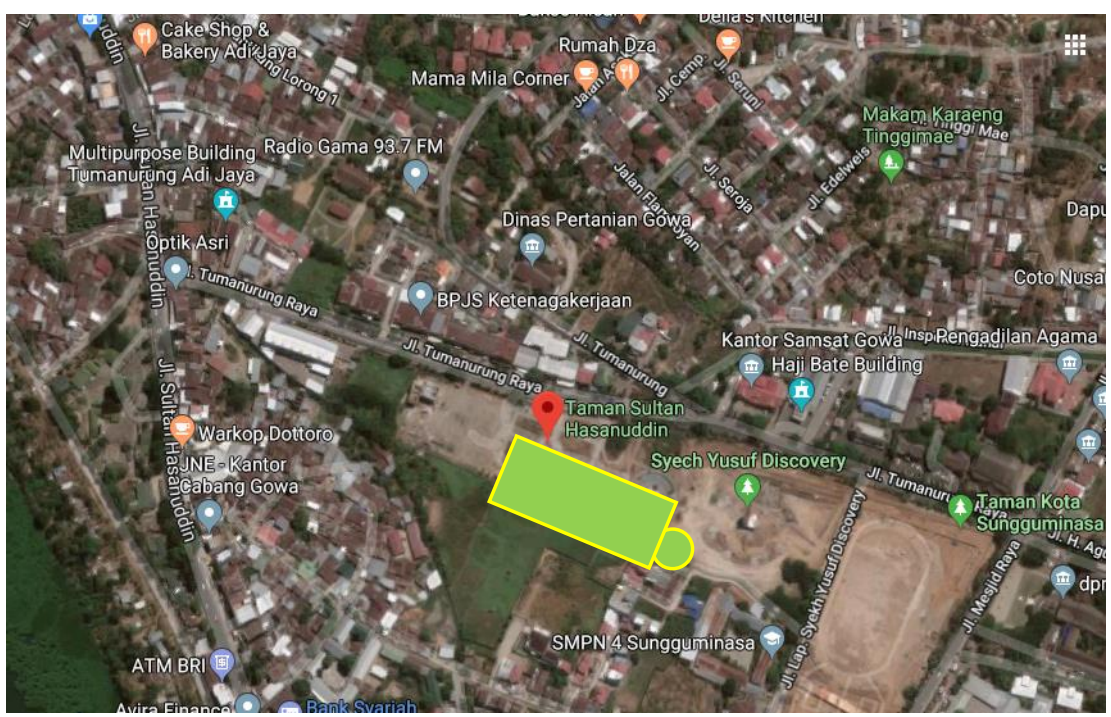

Gambar 1. Lokasi Taman Sultan Hasanuddin

Akses menuju Taman Sultan Hasanuddin dapat ditempuh melalui 2 jalan yaitu Jalan Sultan Hasanuddin dan Jalan Tumanurung. Dari arah Jalan Sultan Hasanuddin dapat diakses dengan Angkutan Umum tetapi, masih perlu berjalan kaki beberapa meter untuk sampai ke Taman. Dari arah Jalan Tumanurung tidak hanya bisa ditempuh dengan kendaraan pribadi atau pejalan kaki.

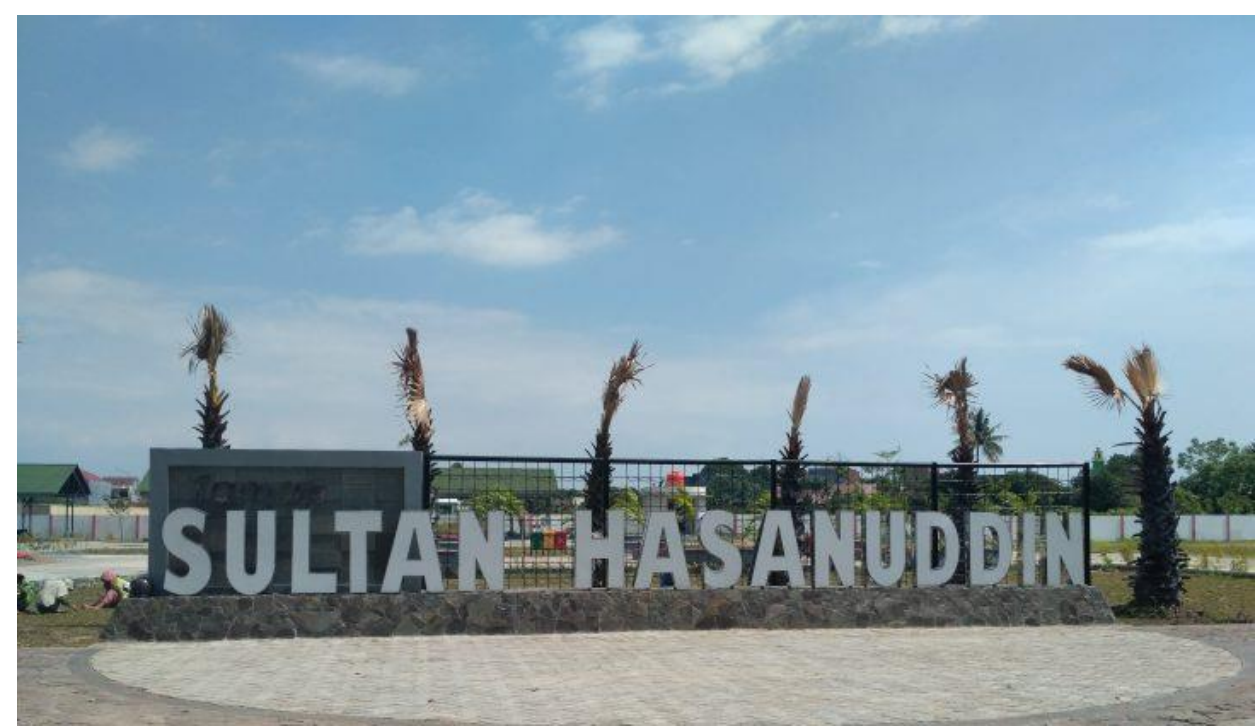

Gambar 2. Taman Sultan Hasanuddin

B. Fasilitas Taman Sultan Hasanuddin

Taman Maccini Sombala of Indonesia luasan area 1 hektar yang mempunyai 2 Plaza dengan fasilitas jogging track/ pedestarian way, Parkiran sepeda, Gazebo, 2 Toilet, Bangku taman, Lapangan sepak bola, Parkiran, Tempat sketboard, tempat istirahat,tempat duduk dan taman. 


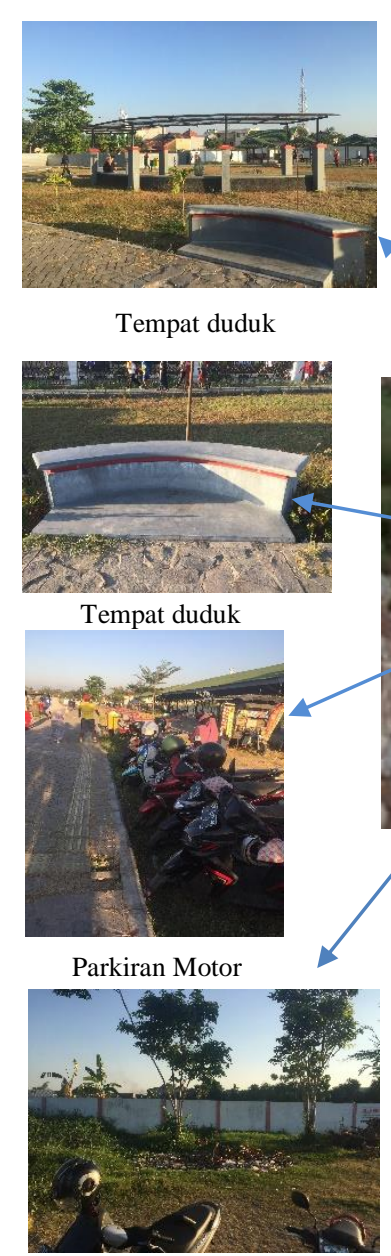

Taman

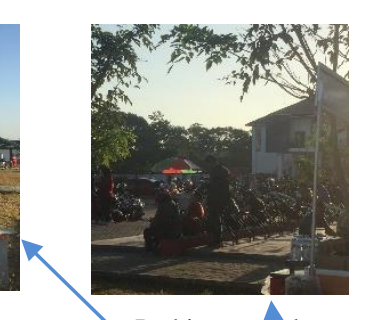

Parkiran sepeda

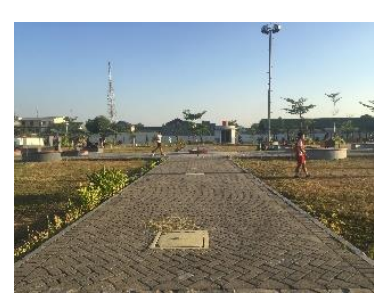

Jogging Track

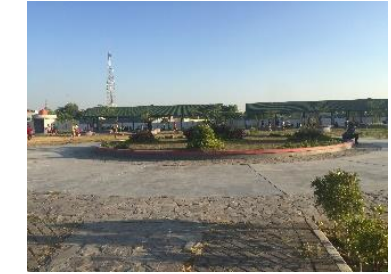

Hal

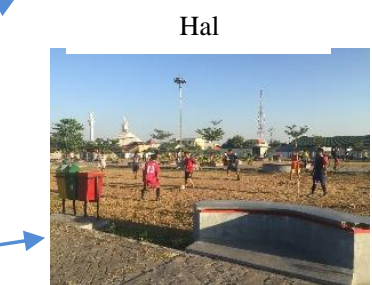

Lapangan Sepak Bola

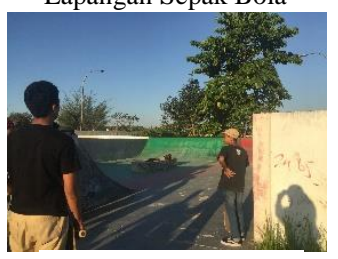

Tempat Sketboard

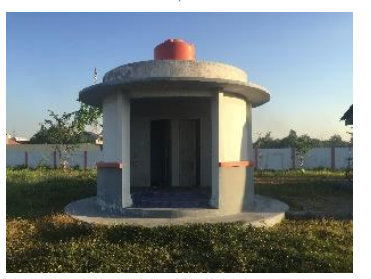

Toilet

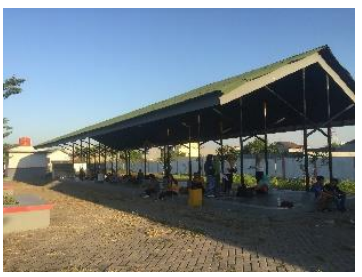

Tempat istirahat

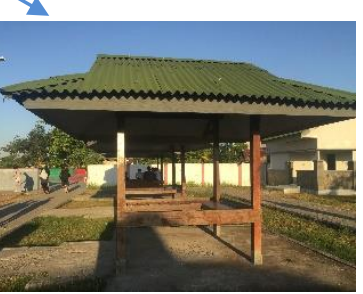

Gazebo

Gambar 3 : Fasilitas Taman Sultan Hasanuddin

C. Analisis Evektifitas pemanfaatan ruang terbuka publik Taman Sultan Hasanuddin

\begin{tabular}{lllcccc}
\hline No. & Existing & \multicolumn{2}{c}{ Fakta } & Penilaian & Bobot & \multicolumn{2}{c}{ Sintesa } \\
\hline 1 & Plaza & Plaza pada Taman & Baik & 3 & Plaza ini \\
& & Sultan Hasanuddin & & & sudah dimanfaatka \\
& terdapat 2 Plaza & & & $\mathrm{n}$ dengan \\
& berbentuk bulat dan & & & baik dan \\
& terdapat taman pada & & & sesuai \\
& bagian tengah. & & fungsinya
\end{tabular}


Irma Rahayu \& Wahyuni Jaharuddin, Evektifitas Pemanfaatan Ruang Terbuka Publik..._ 15

\begin{tabular}{|c|c|c|c|c|c|}
\hline 2 & $\begin{array}{l}\text { Jogging track } \\
\text { pedestrian way }\end{array}$ & $\begin{array}{lr}\text { Jogging track ini } \\
\text { difungsikan oleh } \\
\text { pengunjung } \\
\text { dengan } & \\
\text { peruntukannya } & \\
\text { digunakan untuk } \\
\text { berjalan dan } \\
\text { berlari/berolahraga. }\end{array}$ & Baik & 3 & $\begin{array}{l}\text { - Jalur ini } \\
\text { sudah tertata } \\
\text { baik dan } \\
\text { bersih }\end{array}$ \\
\hline 3 & Parkiran sepeda & $\begin{array}{lr}\text { Parkiran } & \text { sepeda } \\
\text { diperuntukkan } & \text { untuk } \\
\text { parkiran, namun } & \text { kenyataanya } \\
\text { dipergunakan } & \\
\text { sebagaimana } & \\
\text { mestinya. Fasilitas ini } \\
\text { digunakan sebagai } \\
\text { tempat duduk. Hal ini } \\
\text { disebabkan tidak } \\
\text { adanya cycling } & \text { track } \\
\text { pad ataman ini. }\end{array}$ & Buruk & 1 & $\begin{array}{l}\text { - Perlunya } \\
\text { jalur untuk } \\
\text { pengguna } \\
\text { sepeda / } \\
\text { cycling track } \\
\text { sehingga } \\
\text { parkiran } \\
\text { sepeda tidak } \\
\text { salah } \\
\text { fungsikan }\end{array}$ \\
\hline 4 & $\mathrm{Ga}$ & $\begin{array}{l}\text { Gazebo merupakan } \\
\text { fasilitas Ruang } \\
\text { Terbuka Publik yang } \\
\text { difungsikan sebagai } \\
\text { tempat berkumpul } \\
\text { dan bersantai. }\end{array}$ & Cukup baik & 2 & $\begin{array}{l}\text { - Perlunya } \\
\text { pengawasan } \\
\text { untuk } \\
\text { fasilitas } \\
\text { yang } \\
\text { disediakan } \\
\text { agar tidak } \\
\text { rusak. }\end{array}$ \\
\hline 5 & Toilet & $\begin{array}{l}\text { Diperuntukkan bagi } \\
\text { pengunjung Taman } \\
\text { Maccini Sombala } \\
\text { untuk } \\
\text { mengakomodasi } \\
\text { kebutuhan } \\
\text { pengunjung, tetapi } \\
\text { tidak dirawat dengan } \\
\text { baik. }\end{array}$ & Cukup baik & 2 & $\begin{array}{l}\text { - Perlunya } \\
\text { pengawasan } \\
\text { untuk } \\
\text { fasilitas } \\
\text { yang } \\
\text { disediakan } \\
\text { agar tidak } \\
\text { rusak. }\end{array}$ \\
\hline 6 & Bangku Taman & $\begin{array}{l}\text { Tempat duduk pada } \\
\text { taman ini cukup } \\
\text { banyak, tetapi tidak } \\
\text { memiliki peneduh } \\
\text { atau penghalang sinar } \\
\text { matahari, sehingga } \\
\text { tidak berfugsi } \\
\text { sebagimana mestinya }\end{array}$ & Cukup baik & 2 & $\begin{array}{l}\text { - Perlunya } \\
\text { pohon } \\
\text { peneduh } \\
\text { agar lebih } \\
\text { rindang dan } \\
\text { nyaman }\end{array}$ \\
\hline
\end{tabular}




\begin{tabular}{|c|c|c|c|c|c|}
\hline 7 & Lapangan Sepak Bola & $\begin{array}{lr}\text { Tempat } & \text { ini } \\
\text { merupakan } & \text { taman } \\
\text { yang dijadikan } \\
\text { lapangan sepak bola, } \\
\text { karena tidak adanya } \\
\text { fasilitas } \\
\text { bermain bola }\end{array}$ & Buruk & 1 & $\begin{array}{l}\text { - Perlunya } \\
\text { lahan untuk } \\
\text { area } \\
\text { lapangan } \\
\text { sepak bola } \\
\text { agar taman } \\
\text { tidak rusak. }\end{array}$ \\
\hline 8 & Parkiran & $\begin{array}{l}\text { Lahan ini merupakan } \\
\text { pinggiran taman yang } \\
\text { dijakan lahan parkir, } \\
\text { karena tidak adanya } \\
\text { fasilitas lahan parkir } \\
\text { bagi pengunjung. }\end{array}$ & Buruk & 1 & $\begin{array}{l}\text { - Perlunya } \\
\text { lahan parkir } \\
\text { yang jelas } \\
\text { dan lebih } \\
\text { terarah agar } \\
\text { lebih teratur }\end{array}$ \\
\hline 9 & Tempat Sketboard & \begin{tabular}{lr}
\multicolumn{2}{c}{ Tempat sketboard ini } \\
menjadi salah satu \\
fasilitas & yang \\
dimininati & dan \\
dikunjungi bagi anak- & anak muda dan \\
berfungsi & \\
sebagaimana & \\
mestinya &
\end{tabular} & Baik & 3 & $\begin{array}{l}\text { - Sudah } \\
\text { berfungsi } \\
\text { denga baik }\end{array}$ \\
\hline 10 & Tempat Istirahat & $\begin{array}{l}\text { Tempat istirahat ini } \\
\text { berfungsi seperti } \\
\text { gazebo yang kadang } \\
\text { kala difungsikan } \\
\text { sebagai tempat } \\
\text { latihan yoga bagi } \\
\text { sebagian pengunjung, } \\
\text { yang dilengkapi } \\
\text { dengan fasilitas } \\
\text { listrik. }\end{array}$ & Baik & 3 & $\begin{array}{l}\text { - Perlunya } \\
\text { pengawasan } \\
\text { untuk } \\
\text { fasilitas } \\
\text { yang } \\
\text { disediakan } \\
\text { agar tidak } \\
\text { rusak. }\end{array}$ \\
\hline 11 & Tempat duduk & $\begin{array}{l}\text { Tempat duduk pada } \\
\text { taman ini cukup } \\
\text { banyak, tetapi tidak } \\
\text { memiliki peneduh } \\
\text { atau penghalang sinar } \\
\text { matahari, sehingga } \\
\text { tidak berfugsi } \\
\text { sebagimana mestinya }\end{array}$ & $\begin{array}{c}\text { Cukup } \\
\text { Baik }\end{array}$ & 2 & $\begin{array}{l}\text { - Perlunya } \\
\text { pohon } \\
\text { peneduh } \\
\text { agar lebih } \\
\text { rindang dan } \\
\text { nyaman. }\end{array}$ \\
\hline
\end{tabular}




\begin{tabular}{|c|c|c|c|c|c|}
\hline 12 & 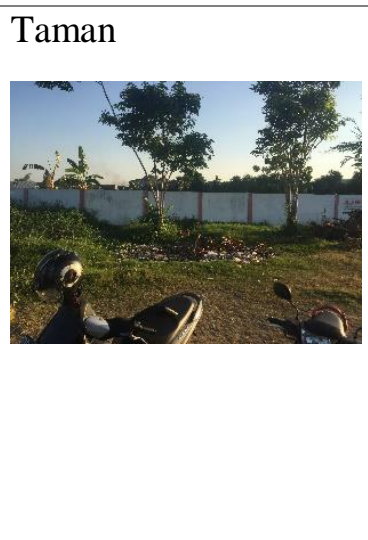 & $\begin{array}{l}\text { Lahan ini merupakan } \\
\text { pinggiran taman yang } \\
\text { tidak terawat dan } \\
\text { dijadikan tempat } \\
\text { sampah umum bagi } \\
\text { sebagian pengunjung } \\
\text { dan orang yang } \\
\text { berjualan di taman } \\
\text { tersebut. }\end{array}$ & Buruk & 1 & $\begin{array}{l}\text { - Perlunya } \\
\text { tempat } \\
\text { sampah } \\
\text { umum } \\
\text { - Perlunya } \\
\text { petugas } \\
\text { kebersihan } \\
\text { untuk } \\
\text { merawat } \\
\text { rumput dan } \\
\text { kebersihan } \\
\text { taman. }\end{array}$ \\
\hline
\end{tabular}

Sumber. Hasil Observasi Peneliti, 2019

Penilaian dari observasi yang dilakukan terdapat 3 indikator yaitu, nilai 3 untuk baik, nilai 2 untuk cukup baik, dan nilai 1 untuk buruk. Dari hasil analisis jumlah indikator dengan penilaian baik sebanyak 4 poin, cukup baik sebanyak 4 poin dan buruk sebanyak 4 poin. Pada tabel analisis dapat dilihat penilaian buruk didominasi olef falisitas pelengkap taman. Dan dari hasil tersebut diatas kemudian dilakukan perkalian jumlah poin dalam kategori penilaian (baik $=6$ poin ,cukup baik $=2$ poin dan buruk $=9$ poin ) dengan bobot penilaian indikator (baik=3, cukup baik=2, buruk=1) untuk mencari jumlah total yang nantinya akan digunakan dalam perhitungan untuk mencari nilai efektivitas taman kota. Untuk mencari nilai total tersebut maka dilakukan perhitungan sebagai berikut :
a. Indikatoruntuk penilaian Baik :
$4 \times 3=12$
b. Indikatoruntuk penilaian Cukup Baik: $4 \times 2=8$
c. Indikatoruntuk penilaian Buruk : $\quad 4 \times 1=4$
Total $=24$

Mencari jarak interval

$$
\begin{aligned}
\text { Jarak Interval } & =(\text { nilai tertinggi }- \text { nilai terendah }) / \text { kelas } \\
& =(3-1) / 3 \\
& =0,7
\end{aligned}
$$
a. pada interval $>2,4-3=$ Efektif
b. pada interval $>1,7-2,4=$ Cukup Efektif
c. pada interval $1-1,7=$ Tidak Efektif

Dari hasil perhitungan nilai total dan jarak interval, dilakukan perhitungan untuk mentukan efektifitas taman kota. Adapun perhitungannya sebagai berikut :

$$
\frac{\text { Total }}{\text { Jumlah indicator }}=\frac{24}{12}=2
$$

Berdasarkan hasil perhitungan dan anlisisnya, diketahui bahwa penilaian terhadap efektivitas Taman Sultan Hasanuddin sebagai Ruang Terbuka Publik di Kabupaten Gowa cukup efektif ( nilai $=2$ ). 
Dari hasil analisis taman masih terdapat beberapa kekurangan, antara lain :

- Tidak adanya petugas keamanan dan kebersihan yang menjaga taman tersebut

- Tidak adanya penerangan/lampu taman yang menjadi daya tarik pengunjung untuk berkunjung pada malam hari.

- Gazebo, toilet umum, pos penjagaan yang merupakan fasilitas penunjuang tamanmengalami kerusakan dan dalam kondisi rusak.

- Tidak adanya tempat sampah yang memadai untuk menampung sampah sehingga pengguna membuang sampah sembarangan.

- Pencapaian dari arah Jalan Tumanurung tidak dapat diakses oleh kendaraan umum, sehingga menyulitkan pengunjung untuk datang ke Taman Sultan Hasanuddin.

\section{KESIMPULAN}

Berdasarkan hasil pembahasan, dapat ditarik 2 kesimpulan yaitu :

1. Berdasarkan kondisi eksisting Taman Sultan Hasanuddin terdapat beberapa hal yang mempengeruhi efektifitas taman sebagai ruang publik di Kabupaten Gowa antara lain:

- Kondisi taman yang tidak memiliki petugas kebersihan dan tidak adanya pengawasan mengakibatkan Taman Sultan Hasanuddin kurang terawat dan fasilitas rusak.

- Tidak adanya penerangan/lampu taman yang menjadi daya tarik pengunjung untuk berkunjung pada malam hari.

- Pencapaian dari arah Jalan Tumanurung tidak dapat diakses oleh kendaraan umum, sehingga menyulitkan pengunjung untuk datang ke Taman Sultan Hasanuddin.

2. Dari hasil penilaian yang didapatkan, Taman Sultan Hasanuddin di Kabupaten Gowa terbilang cukup evektif, akan tetapi masih memiliki beberapa kekurangan antara lain:

- Gazebo, toilet umum, pos penjagaan yang merupakan fasilitas penunjuang taman mengalami kerusakan dan dalam kondisi rusak

- Tidak adanya tempat sampah yang memadai untuk menampung sampah sehingga pengguna membuang sampah sembarangan.

\section{DAFTAR PUSTAKA}

Carr, S, (1992). Public Space .Australia : Press Syndicate of University of Cambridge. Dalam jurnal Rivino,Efektivitas Ruang Terbuka Publik Kecamatan Sario Kota Manado.

Darmawan,E,2009, Ruang Publik Dalam Perancangan Kota, Badan Penerbit UNDIP, Semarang

Handayaningrat, S.(2002), Pengantar Suatu Ilmu Administrasi Dan Manajemen, Gunung Agung, Jakarta. Dalam jurnal Rivino,Efektivitas Ruang Terbuka Publik Kecamatan Sario Kota Manado.

Krier,Rob. (1979). Urban Space. Terjemahan oleh Ir. Effendi Setiadharma, dkk. Jakarta: Penerbit Erlangga.

Meira,S. (2002). Analisis efektivitas taman kota melalui pendekatan kondisi tapak dan perilaku pengunjung. Tesis , Bogor Agricultural University. Bogor. Dalam jurnal Rivino,Efektivitas Ruang Terbuka Publik Kecamatan Sario Kota Manado. 
Irma Rahayu \& Wahyuni Jaharuddin, Evektifitas Pemanfaatan Ruang Terbuka Publik..._ 19

Rahayu, E. (2005). Studi Persepsi Terhadap Faktor-Faktor Yang Mempengaruhi Tingkat Kenyamanan Kawasan Simpang Lima Sebagai Ruang Terbuka Publik. Skripsi.Jurusan Perencanaan Wilayah Dan Kota. Universitas Diponegoro. Semarang. Dalam jurnal Rivino,Efektivitas Ruang Terbuka Publik Kecamatan Sario Kota Manado.

Riri,E.(2015). Evaluasi Pemanfaatan Fungsi Taman Tematik Sebagai Urban Landscape Dalam Upaya Perwujudan Green City,Bandung.

Shalli(2014). Efektivitas Taman Swedari sebagai Ruang Publik di Kota Surakarta. https://gosulsel.com/2017/08/23/taman-sultan-hasanuddin-ruang-publik-baru-di-pusatsungguminasa/ 